\title{
Pengaruh Penyuluhan 1000 Hari Pertama Kehidupan (HPK) pada Pasangan Usia Subur di Perkotaan dan Perdesaan
}

\author{
Agus Hendra Al Rahmad \\ Jurusan Gizi, Politeknik Kesehatan Kemenkes Aceh, Indonesia \\ Email: 4605.ah@gmail.com
}

\begin{abstract}
The Effect of Counseling on the First 1000 Days of Life in Couples of Childbearing Age in Urban and Rural Areas. Nutrition improvements in the group of the first 1000 days of life will support the growth process from pregnancy to children aged 2 years. The main factor of nutrition improvement is knowledge about the first 1000 days of life. Nutritional adequacy in the first 1000 days of life affects the lives of infants and children aged 2 years, Aceh province shows $23,7 \%$ of Aceh children suffer from malnutrition. Then to increase knowledge, conducted counseling about the first 1000 days of life. The goal is to compare the effectiveness of counseling to increase knowledge of couples of childbearing age in urban and rural areas. Quantitative research designed quasi-experiment. Samples are 100 couples people. The location of the research was conducted in Baiturrahman and Darul Kamal Subdistricts, research was conducted on 26-28 July 2017. Data collection includes primary and secondary data, Then processed through the stages of editing, coding, processing, and cleaning. Data analysis using T-Test. The Results, there is an increasing influence of counseling the first 1000 days of life to couples of childbearing age in urban and rural areas, with $\mathrm{p}<0,05$. Counseling the first 1000 days of life to have better effectiveness in improving knowledge couples of childbearing age, with $\mathrm{p}<0,05$. While the comparison of knowledge, the average score in urban (50) is higher compared with rural (45). Conclusion, counseling the first 1000 days of life take effect to Increased knowledge of couples of childbearing age and have better effectiveness, as well as a higher knowledge increase in urban areas than in rural areas.
\end{abstract}

Keywords: Counseling, Couples of childbearing age, Knowledge, The first 1000 days of life

\begin{abstract}
Abstrak: Pengaruh Penyuluhan 1000 HPK pada Pasangan Usia Subur di Perkotaan dan Perdesaan. Perbaikan gizi pada kelompok 1000 HPK akan menunjang proses tumbuh kembang dari kehamilan sampai usia 2 tahun. Faktor utama dari perbaikan gizi yaitu pengetahuan tentang 1000 HPK. Kecukupan gizi pada 1000 HPK mempengaruhi kehidupan bayi dan anak usia 2 tahun, provinsi aceh menunjukkan 23,7\% anak aceh mengalami gizi buruk. Maka untuk meningkatkan pengetahuan, dilakukan penyuluhan tentang 1000 HPK. Tujuannya untuk membandingkan efektifitas penyuluhan terhadap peningkatan pengetahuan pasangan usia subur di perkotaan dan perdesaan. Penelitian kuantitatif berdesain experiment semu. Sampel berjumlah 100 pasangan. Lokasi penelitian dilakukan di Kecamatan Baiturrahman (Banda Aceh) dan Darul Kamal (Aceh Besar), penelitian dilakukan pada Juni-Juli 2017. Pengumpulan data meliputi data primer dan sekunder, diolah melalui tahapan editing, coding, processing, dan cleaning, analisis data menggunakan uji T-Test. Hasil menunjukan, terdapat peningkatan pengaruh penyuluhan $1000 \mathrm{HPK}$ pada pasangan usia subur di perkotaan dan perdesaan, dengan $p$-value $<0,05$. Penyuluhan $1000 \mathrm{HPK}$ mempunyai efektivitas yang lebih baik dalam meningkatkan pengetahuan pasangan usia subur, dengan $p$-value $<0,05$. Sedangkan perbandingan pengetahuan, rata-rata skor di perkotaan (50) lebih tinggi dibandingkan dengan perdesaan (45). Penyuluhan 1000 HPK berpengaruh terhadap peningkatan pengetahuan PUS, dan mempunyai efektivitas yang lebih baik, serta peningkatan pengetahuan lebih tinggi terdapat pada daerah perkotaan dibandingkan daerah perdesaan.
\end{abstract}

Kata kunci: Penyuluhan, Pasangan Usia Subur, Pengetahuan, 1000 HPK

Gerakan Nasional Sadar Gizi dalam rangka percepatan perbaikan gizi pada 1000 Hari Pertama Kehidupan disingkat dengan gerakan 1000 HPK. 1000 HPK adalah fase kehidupan yang dimulai sejak terbentuknya janin dalam kandungan $(270$ hari) sampai berusia 2 tahun (730 hari). Periode ini jika tidak dimanfaatkan dengan baik akan terjadi kerusakan yang bersifat permanen (window of opportunity) (Bappenas, 2012). Dampak tersebut tidak hanya pada pertumbuhan fisik, 
tetapi juga pada perkembangan mental dan kecerdasan, ketika dewasa akan terlihat dari ukuran fisik yang tidak optimal serta kualitas kerja yang tidak kompetitif yang berakibat pada rendahnya produktivitas dan ekonomi (Bappenas, 2015).

Masa subur seorang wanita memiliki peran penting bagi kehamilan, sehingga peluang wanita biasanya terdapat diantara 15-49 tahun. Berdasarkan data Riskesdas pada tahun 2013, BBLR yang terjadi pada tahun 2010 (10,2\%) meningkat tahun $2013(11,1 \%)$ begitu juga dengan pemberian ASI eksklusif sebesar pada tahun 2010 (15,3\%) meningkat tahun 2013 (38\%) sedangkan presentase gizi lebih pada balita sebesar tahun $2010(5,8 \%)$ mengalami peningkatan pada tahun $2013(11,9 \%)$. Selain itu prevalensi pendek (stunted) pada tahun $2013(37,2 \%)$ prevalensi sangat kurus (severely wasted) pada tahun 2013 sebesar 5,3\% (Balitbangkes, 2013a).

Kecukupan gizi sangat mempengaruhi kehidupan bayi dan anak-anak dibawah usia lima tahun, data menunjukkan 23,7\% anak Aceh mengalami gizi buruk. Kondisi ini akan berpengaruh besar terhadap angka kematian bayi. Kematian bayi di Aceh merupakan akibat kekurangan gizi, baik kala janin masih berada di dalam kandungan atau pun usia bayi masih di bawah satu tahun (Balitbangkes, 2013b). Dinas Kesehatan Aceh mencatat, kematian bayi meningkat dari tahun ke tahun, dilihat dari angka kematian bayi yang mencapai 1.034 kasus pada tahun 2013, angka kematian ini naik sekitar 5\% dibandingkan pada tahun 2012 yang berjumlah 985 bayi (Dinkes Aceh, 2016).

Wanita mempunyai peran penting dalam membeli dan menyiapkan makanan dan mendidik anggota keluarga tentang makanan sehat (Halimatussakdiah \& Miko, 2016). Selain itu, peran seorang wanita yang erat kaitannya dengan kedudukannya dalam keluarga, wanita berperan penting dalam memelihara kesehatan keluarga, menyiapkan makanan bergizi setiap hari dan bertanggung jawab terhadap sanitasi rumah tangga juga menciptakan pola hidup sehat jasmani, rohani dan social (Al Rahmad \& Miko, 2017). Terutama pada masa $1000 \mathrm{HPK}$, bagi wanita yang tengah mempersiapkan kehamilan, penting bagi mereka untuk mengetahui tentang gizi seimbang mulai dari awal kehamilan sampai anak usia dua tahun agar bayi lahir sehat serta terhindar dari berbagai masalah gizi (Zahraini, 2013). Berdasarkan data Riskesdas 2013, tingginya masalah gizi yang terjadi di Kabupaten Aceh Besar dibandingkan Kota Banda Aceh terdapat banyak permasalahan dalam kehidupan keluarga, seperti karakteristik keluarga pendidikan pekerjaan orang tua serta faktor tempat tinggal. Kondisi yang bertempat tinggal di perdesaan ikut serta dalam tingginya prevalensi gangguan gizi anak (Balitbangkes, 2013a).

Pasangan Usia Subur juga harus diberikan penyuluhan agar mereka mengerti akan pentingnya 1000 hari pertama kehidupan di masa awal kehamilan hingga anak berusia dua tahun. Pasangan Usia subur memerlukan penyuluhan/ promosi kesehatan dalam kehidupannya, dalam hal ini petugas kesehatan haru mempromosikan berbagai hal mengenai keluarga sehat, atau bahkan mengenai kehidupan kekeluargaan dalam rumah tangga, dan 1000 hari pertama kehidupan adalah promosi kesehatan yang wajib dilakukan karena berdampak besar bagi kehidupan nantinya (Melly \& Magdalena, 2018). Dengan adanya penyuluhan 1000 hari pertama kehidupan ini, diharapkan angka kematian bayi dan ibu menurun serta dapat meningkatkan kecerdasan.

Penyuluhan sangat efektif dalam menunjang perubahan pengetahuan, oleh karena itu untuk meningkatkan pengetahuan ibu dapat dilakukan dengan menerapkan penyuluhan dengan media sebagai alat bantu (Musfiroh \& Wisudaningtyas, 2014). Menurut Kusumawardani, bahwa melalui penyuluhan menggunakan media flipchart dan metode ceramah, secara signifikan mempunyai peningkatan pengetahuan sebesar $17,6 \%$ setelah dilakukan penyuluhan, ini menunjukkan bahwa media mempunyai peran penting dalam melaksanakan penyuluhan (Kusumawardani et al, 2012).

Selain itu, keberadaan anak-anak stunting di Aceh menjadi salah satu kekhawatiran tersendiri karena jumlahnya yang melampaui angka rata-rata nasional, rerata jumlah anak yang mengalami stunting menunjukkan angka 38,9 persen (Al Rahmad et al, 2013). Hal ini disebabkan oleh faktor pengetahuan ibu yang masih rendah tentang perlunya 1000 Hari Pertama Kehidupan.

\section{METODE}

Penelitian eksperimen ini menggunakan desain Quasi Experimental melalui pretest posttest non equivalent group yaitu suatu pendekatan eksperimen yang mengontrol situasi rancangan sebelum dan sesudah intervensi menggunakan dua kelompok sebagai pembanding, dengan sarasan bersifat non-random assignment. Penelitian dilaksanakan di Kota Banda Aceh dan Kabupaten Aceh Besar dengan melibatkan 100 pasangan usia pasien dari beberapa daerah terpilih, kelompok sampel dibagi menjadi kelompok perkotaan 
(kecamatan Baiturahman dalam Kota Banda Aceh) dan kelompok perdesaan (kecamatan Darul Kamal dalam Kabupatyen Aceh Besar). Penyuluhan hanya dilakukan satu kali. Penelitian dilaksanakan Juni-Juli 2017.

Pengumpulan data dilakukan secara wawancara. Data yang dikumpulkan yaitu data karakteristik pasien diperoleh secara wawancara menggunakan kuesioner berisi 25 butir pertanyaan dalam bentuk multiple choise, baik sebelum diberikan intervensi maupun setelah diintevensi. Model intervensi penyuluhan yaitu menggunakan media ceramah tentang tentang pentingnya 1000 hari pertama kehidupan, dengan rincian materi yaitu pengertian $1000 \mathrm{HPK}$, sasaran, pentingnya 1000 HPK, dan dampak serta akibatnya. Proses penyuluhan dilakukan oleh peneliti sendiri dan dibantu 4 orang enumerator dari lulusan/alumni gizi.

Analisis data pada penelitian ini menggunakan aplikasi statistik. Pengujian prasyarat analisis penting dilakukan pada pendekatan statistik parametrik mengingat model distribusi dan variansi antar kelompok data yang ada. Pengujian pra-syarat analisis menggunakan uji Kolmogorov Smirnov diperoleh bahwa data kadar kolesterol berdistribusi normal ( $p$-value $>0,05)$, pengujian normalitas dilakukan terhadap data pengetahuan responden baik sebelum diberikan penyuluhan maupun setelah penyuluhan. Selanjutnya dalam menjawab tujuan penelitian serta membuktikan hipotesis, digunakan analisis uji statistik yaitu dependent t-test dan independent T-test yaitu untuk mengukur pengaruh penyuluhan terhadap pengetahuan responden tentang $1000 \mathrm{HPK}$.

\section{HASIL}

\section{Karakteristik Responden}

Responden pada penelitian ini merupakan Pasangan Usia Subur (PUS) yang berada di dua kecamatan yaitu kecamatan Baiturrahman (daerah perkotaan) dan Darul Kamal (daerah perdesaan) yang diambil sebanyak 100 pasangan. Berdasarkan hasil penelitian terkait karakteristik responden (Tabel 1), tergambarkan secara umum responden berusia antara 21-30 tahun dan berpendidikan SLTA dan Diploma, selanjutnya berdasarkan pekerjaan ditemukan bahwa IRT lebih dominan, namun demikian pekerjaan responden sebagai swasta dan wiraswasta juga lebih banyak.

Hasil uji statistik menunjukan bahwa kedua kelompok sampel tidak menunjukan perbedaan secara proporsional $(p>0,05)$, terlihat hampir menunjukan proporsi yang sama pada setiap karakteristik seperti proporsi umur pada kedua kelompok umumnya antara 21-30 tahun, begitu juga dengan pendidikan yaitu mayoritas berpendidikan SLTA dan Diploma.

\begin{tabular}{lccccc} 
Tabel 1. Karakteristik Responden \\
\cline { 2 - 5 } $\begin{array}{l}\text { Karakteristik } \\
\text { Sampel }\end{array}$ & \multicolumn{2}{c}{ Perkotaan } & \multicolumn{2}{c}{ Perdesaan } & p-value \\
\cline { 2 - 5 } n & \% & n & \% & \\
\hline Umur & & & & & \\
$15-20$ tahun & 12 & 24,0 & 14 & 28,0 & 0,238 \\
$21-30$ tahun & 28 & 56,0 & 20 & 40,0 & \\
$31-40$ & 10 & 20,0 & 16 & 32,0 & \\
\hline Pendidikan & & & & & \\
SD & 2 & 4,0 & 5 & 10,0 & 0,309 \\
SLTP & 5 & 10,0 & 8 & 16,0 & \\
SLTA & 14 & 28,0 & 17 & 34,0 & \\
Diploma & 18 & 36,0 & 15 & 30,0 & \\
Sarjana & 11 & 22,0 & 5 & 10,0 & \\
\hline Pekerjaan & & & & & \\
Buruh & 2 & 4,0 & 8 & 16,0 & 0,175 \\
Swasta & 10 & 20,0 & 7 & 14,0 & \\
Wiraswasta & 12 & 24,0 & 11 & 22,0 & \\
PNS & 9 & 18,0 & 4 & 8,0 & \\
IRT & 17 & 34,0 & 20 & 40,0 & \\
\hline$\quad$ Jumlah & 50 & 100,0 & 50 & 100,0 & \\
\hline
\end{tabular}

Berdasarkan pekerjaan, antara kelompok perlakuan diperkotaan dengan perdesaan masing-masing hampir mempunyai proporsi yang sama, yaitu bekerja sebagai IRT. Sehingga dapat dipastikan bahwa variabel karakteristik bukan sebagai faktor perancu terhadap pengaruh penyuluhan terhadap pengetahuan pasangan usia subur tentang 1000 HPK.

\section{Pengetahuan PUS tentang 1000 HPK}

Hasil penelitian sebagaimana disajikan pada Tabel 2, menunjukan bahwa rerata skor pengetahuan pasangan usia subur tentang 1000 HPK didaerah perkotaan sebelum diberikan penyuluhan yaitu 41,1 dan setelah diberikan penyuluhan menjadi 59,9. Sedankgkan didaerah perdesaan skor pengetahuan sebelum diberikan penyuluhan yaitu 39,1 dan menjadi 52,4 setelah diberikan penyuluhan. Hasil tersebut menunjukan peningkatan pengetahuan setelah diberikan penyuluhan, namun rerata pengetahuan responden diperkotaan lebih tinggi dibandingkan didaerah perdesaan.

Pemberian penyuluhan guna membagikan suatu informasi kepada seseorang atau sekelompok orang sangatlah penting, salah satunya yaitu penyuluhan pada pasangan usia subur untuk meningkatkan pengetahuan mereka agar menjadi lebih baik. Pendidikan jelas sangat mempengaruhi peningkatan pengetahuan, karena semakin tinggi pendidikan maka semakin luas ilmu dan wawasan yang dimilikinya. Hal tersebut sangat 
berkaitan dengan seseorang ataupun individu yang berpendidikan tinggi akan lebih mudah menangkap serta memahami suatu informasi yang diterimanya dibandingkan dengan yang berpendidikan rendah.

\section{Pengaruh Penyuluhan terhadap Pengetahuan PUS tentang 1000 HPK}

Perbandingan pada setiap kondisi karakteristik responden seperti proporsi umur, pendidikan, dan pekerjaan menunjukan kesamaan atau berasal dari kelompok yang sama dan tidak menunjukan perbedaan proporsi antara kelompok responden dari perkotaan dengan responden dari perdesaan, sebagaimana hasil yang telah disajikan pada Tabel 1. Sehingga dapat dipastikan bahwa variabel karakteristik bukan sebagai faktor perancu terhadap pengaruh penyuluhan terhadap peningkatan pengetahuan tentang 1000 HPK pada pasangan usia subur di Kota Banda Aceh dan Aceh Besar.

Hasil statistik sebagaimana Tabel 2, diketahui bahwa terjadi peningkatan skor pengetahuan setelah diberikan intervensi berupa penyuluhan tentang 1000 HPK, baik didaerah perkotaan maupun di daerah perdesaan.
Peningkatan skor pengetahuan pada pasangan usia subur pada kelompok perkotaan yaitu sebesar 18,8 dengan deviasi 9,40. Secara statistik terbukti bahwa terdapat perbedaan signifikan $\quad(p$-value $<0,01)$ antara skor pengetahuan sebelum dengan setelah pemberian penyuluhan pada PUS tentang 1000 HPK, dengan nilai $p=0,000$. Hasil statistik tersebut dapat disimpulkan bahwa penyuluhan tentang 1000 HPK menggunakan metode ceramah dapat meningkatkan pemahaman pasangan usia subur tentang pentingnya 1000 HPK di Kota Banda Aceh.

Selanjutnya juga terjadi peningkatan skor pengetahuan pada kelompok perdesaan yang juga mendapatkan penyuluhan gizi dengan metode ceramah. Peningkatan tersebut relatif lebih kecil yaitu sebesar 13,3 dengan deviasi sebesar 6,06. Hasil statistik (Tabel 2), juga membuktikan terdapat perbedaan signifikan ( $p$-value $<0,01)$ antara skor pengetahuan PUS sebelum diberikan penyuluhan dengan setelah diberikan penyuluhan tentang 1000 HPK, dengan nilai $p=0,000$. Hal ini menunjukan bahwa, penyuluhan gizi tentang 1000 HPK dapat meningkatan pemahaman pasangan usia subur yang relatif baik tentang 1000 HPK di Kabupaten Aceh Besar.

Tabel 2. Skor Pengetahuan Sebelum dan Sesudah Pemberian Penyuluhan tentang 1000 HPK pada Pasangan Usia Subur di Kota Banda Aceh dan Aceh Besar

\begin{tabular}{|c|c|c|c|c|c|}
\hline $\begin{array}{c}\text { Pengetahuan PUS tentang } \\
1000 \text { HPK pada Kelompok } \\
\text { Intervensi }\end{array}$ & Min - Max & Rerata \pm SD & $\begin{array}{c}\text { Selisih Rerata } \\
\pm \text { SD }\end{array}$ & CI: $95 \%$ & $p$-value \\
\hline \multicolumn{6}{|l|}{ Daerah Perkotaan } \\
\hline Sebelum Penyuluhan & $29,0-55,0$ & $41,1 \pm 8,25$ & $18,8 \pm 9,40$ & $16,23 \mathrm{~s} / \mathrm{d} 21,36$ & $0,000^{*}$ \\
\hline Setelah Penyuluhan & $49,0-68,0$ & $59,9 \pm 6,28$ & & & \\
\hline \multicolumn{6}{|l|}{ Daerah Perdesaan } \\
\hline Sebelum Penyuluhan & $34,0-45,0$ & $39,1 \pm 3,48$ & $13,3 \pm 6,06$ & $11,93 \mathrm{~s} / \mathrm{d} 15,18$ & $0,000^{*}$ \\
\hline Setelah Penyuluhan & $44,0-59,0$ & $52,4 \pm 5,65$ & & & \\
\hline
\end{tabular}

\section{PEMBAHASAN}

\section{Pengaruh Penyuluhan terhadap Pengetahuan PUS tentang 1000 HPK}

Hasil penelitian menunjukan terdapat pengaruh signifikan pemberian penyuluhan tentang 1000 HPK terhadap peningkatan pengetahuan pasangan usia subur, baik diderah perkotaan maupun didaerah perdesaan.

Pelaksanaan penyuluhan gizi dan kesehatan melalui media sangat mendukung terhadap perubahan pengetahuan kesehatan khususnya bidang gizi. Walaupun demikian, penyuluhan tanpa media juga dapat merubah pengetahuan, akan tetapi media mempunyai nilai efektifitas yang lebih baik dalam meningkatkan pengetahuan (Al Rahmad \& Almunadia, 2017).

Sesuai dengan beberapa pendapat para peneliti yaitu Al Rahmad \& Miko (2017), pengetahuan bukan hanya dari keyakinan atau kepercayaan individu melainkan suatu usaha untuk mencari tahu, atau melalui pengalaman pribadi bersama orang lain dan pengetahuan tentang 1000 HPK bukan hanya diperoleh melalui pendidikan formal tetapi bisa melalui informasi dari rekan yang berlatar belakang kesehatan maupun dari media massa (Al 
Rahmad \& Miko, 2017).

Penyuluhan kesehatan dapat menambah pengetahuan dan kemampuan seseorang melalui teknik belajar atau instruksi yang bertujuan untuk mengubah atau mempengaruhi perilaku manusia secara individual maupun kelompok ataupun masyarakat untuk dapat lebih mandiri dalam mencapai tujuan hidup sehat (Iskandarsyah, 2016). Peningkatan pengetahuan seseorang juga berkaitan dengan cara penyampaian serta isi materi yang disampaikan, penyampaian yang dilakukan dengan cara yang baik dan benar akan menimbulkan hasil yang baik (Wilis \& Al Rahmad, 2018). Penyuluhan tersebut juga berguna untuk mengubah prilaku masyarakat dalam meningkatkan pengetahuan 1000 HPK, mengubah pola fikir yang baik dan benar tentang konsumsi makanan yang baik dan benar, serta memberikan penambahan ilmu baru tentang pentingnya masa kehamilan hingga anak berusia dua tahun (Halimah, 2018).

Penyuluhan kesehatan merupakan suatu penyampain pesan atau informasi kesehatan kepada penerima (responden) secara langsung maupun secara tidak langsung. Perbandingan diantara dua kecamatan tersebut ketika diberikan penyuluhan yaitu pada kelompok perkotaan para pasangan usia subur lebih antusias mendengarnya dan cepat memahami materi yang diberikan, sedangkan pada kelompok perdesaan para pasangan usia subur hanya mendengarkan akan tetapi kurang memahami apa yang telah dijelaskan oleh pemberi materi (Ratag \& Kawatu, 2018).

Penyuluhan 1000 hari pertama kehidupan ini, mempunyai perbandingan yang efektif antara perkotaan dan perdesaan dapat dilihat pada hasil penelitian yang menunjukkan perkotaan lebih tinggi dibanding perdesaan, ada beberapa faktor yang mempengaruhi peningkatan pengetahuan, Salah satu adalah dikarenakan di wilayah perkotaan akses terhadap informasi lebih mudah didapatkan dibandingkan dengan di wilayah perdesaan. Banyak akses untuk mengetahui informasi terbaru, diperkotaan akses terhadap informasi lebih cepat dibandingkan di perdesaan baik itu dari media massa dan lainnya (Kesetyaningsih et al, 2016).

Pengetahuan seseorang juga berpengaruh terhadap pendidikan, usia dan akses terhadap media yang digunakan, perkotaan adalah tempat yang kaya akan akses informasi, jadi tidak ada kemungkinan mereka kekurangan informasi, lain hal dengan daerah perdesaan yang minim dengan akses media informasi, hanya saja mereka yang hidup di daerah perdesaan mau berusaha untuk mencari informasi atau tidak, dikarenakan usaha mereka adalah salah satu cara memperbaiki pengetahuan serta meningkatkan pengetahuannya (Trisnawati et al, 2016).

\section{SIMPULAN}

Penyuluhan gizi tentang 1000 Hari Pertama Kehidupan (HPK) yang diberikan kepada pasangan usia subur secara siginifikan dapat meningkatan pengetahuan dan pemahaman mereka tentang pentingnya 1000 hari pertama kehidupan baik terkait pengertian, sasaran, maupun dampak serta akibatnya. Pengetahuan tentang 1000 HPK bukan saja dapat ditingkatkan pada masyarakat perkotaan di Kota Banda Aceh, namun penyuluhan juga dapat meningkatkan pengetahuan pada masyarakat perdesaan di Kabupaten Aceh Besar.

\section{DAFTAR PUSTAKA}

Al Rahmad, A. H., \& Almunadia, A. (2017). Pemanfaatan Media Flipchart dalam Meningkatkan Pengetahuan Ibu Tentang Konsumsi Sayur dan Buah. Jurnal Kedokteran Syiah Kuala, 17(3), 140-146.

AL Rahmad, A. H., Miko, A., \& Hadi, A. (2013). Kajian Stunting Pada Anak Balita Ditinjau Dari Pemberian ASI Eksklusif, MP-ASI, Status Imunisasi Dan Karakteristik Keluarga Di Kota Banda Aceh. Jurnal Kesehatan Ilmiah Nasuwakes Poltekkes Aceh, 6(2), 169-184.
Al Rahmad, A., \& Miko, A. (2017). Peningkatan Pengetahuan Calon Pengantin melalui Konseling ASI Eksklusif di Aceh Besar. Indonesian Bulletin of Health Research, 45(4), 249-256.

Balitbangkes. (2013a). Riset Kesehatan Dasar 2013 (Pertama). Jakarta: Badan Penelitian dan Pengembangan Kesehatan. https://doi.org/1 Desember 2013

Balitbangkes. (2013b). Riset Kesehatan Dasar 2013 Berdasarkan Provinsi Aceh. (S. Herman \& N. Puspasari, Eds.) (Pertama). 
152 Jurnal Kesehatan, Volume 10, Nomor 1, April 2019, hlm 147-152

Banda Aceh: Badan Penelitian dan Pengembangan Kesehatan Kementerian Kesehatan RI. Retrieved from terbitan.litbangkes.depkes.go.id

Bappenas. (2015). Laporan Pencapaian Tujuan Pembangunan Milenium di Indonesia 2014 (Kesembilan). Jakarta: Kementerian Perencanaan Pembangunan Nasional.

Dinkes Aceh. (2016). Profil Kesehatan Aceh Tahun 2015. Banda Aceh.

Halimah, R. S. (2018). Pengaruh Metode Ceramah denganPemutaran Video dan Metode Ceramah terhadap Peningkatan Pengetahuan danSikap Ibu Hamil tentang ASI Eksklusif diKecamatan Perbaungan Tahun 2018. Universitas Sumatera Utara. http://repositori.usu.ac.id/handle/123456789 16037

Halimatussakdiah, H., \& Miko, A. (2016). Hubungan Antropometri Ibu Hamil (Berat Badan, Lingkar Atas, Tinggi Fundus Uteri) dengan Reflek Fisiologi Bayi Baru Lahir Normal. AcTion: Aceh Nutrition Journal, 1(2), 88-93.

Iskandarsyah, M. N. (2016). Pelaksanaan Strategi Promosi Kesehatan dalam Program Perilaku Hidup Bersih dan Sehat (PHBS) Tatanan Rumah Tangga di Puskesmas Puuwatu Kota Kendari Tahun 2015. Kendari: FKM Universitas Halu Oleo.

Kesetyaningsih, T. W., Alislam, H. M., \& Eka, F. (2016). Kepadatan Larva Aedes Aegypti di Daerah Endemis Demam Berdarah Desa dan Kota, Hubungannya dengan Pengetahuan dan Perilaku Masyarakat. Mutiara Medika: Jurnal Kedokteran Dan Kesehatan, 12(1), $56-62$.

Kusumawardani, E., Arkhaesi, N., \& Hardian, H.
(2012). Pengaruh Penyuluhan Kesehatan Terhadap Tingkat Pengetahuan, Sikap dan Praktik Ibu Dalam Pencegahan Demam Berdarah Dengue Pada Anak. (Skripsi, Fakultas Kedokteran UNDIP).

Melly, M., \& Magdalena, M. (2018). Pengaruh Penyuluhan Metode Ceramah dan Audio-Visual Terhadap Pengetahuan Ibu Hamil Tentang 1000 HPK Di Puskesmas Sidomulyo Rawat Inap Kota Pekanbaru. Mahakam Midwifery Journal (MMJ), 2(4), 255-266.

Musfiroh, M., \& Wisudaningtyas, B. L. (2014). Penyuluhan Terhadap Sikap Ibu Dalam Memberikan Toilet Training Pada Anak. Jurnal Kesehatan Masyarakat, 9(2), 157-166.

Ratag, B. T., \& Kawatu, P. A. T. (2018). Pengetahuan, Sikap Dan Tindakan Masyarakat Di Wilayah Kabupaten Minahasa Utara Tentang Pemberian Air Susu Ibu Eksklusif. KESMAS, 7(1), 1-7.

Trisnawati, Y., Purwanti, S., \& Retnowati, M. (2016). Studi Deskriptif Pengetahuan dan Sikap Ibu Hamil tentang Gizi 1000 Hari Pertama Kehidupan di Puskesmas Sokaraja Kabupaten Banyumas. Jurnal Kebidanan, 8(02), 127-224.

Wilis, R., \& Al Rahmad, A. H. (2018). Penggunaan Modul Pendamping Kms Terhadap Ketepatan Kader Menginterpretasi Hasil Penimbangan. Jurnal Vokasi Kesehatan, 4(1), 12-18.

Zahraini, Y. (2013). 1000 Hari Pertama Kehidupan: Mengubah Hidup, Mengubah Masa Depan.

http://gizi.depkes.go.id/1000-hari-menguba h-hidup-mengubah-masa-depan 